\title{
IMPLICAÇÕES DAS AVALIAÇÕES EXTERNAS NA ALFABETIZAÇÃO.
}

Onaide Mendonça, Anna Marina Rauseo, Beatriz Bertasso Sanches, Nayara Moreira Camargo.

Universidade Estadual Paulista - UNESP, Licenciatura em Pedagogia, Presidente Prudente, SP. E-mail: onaideschwartz66@hotmail.com.

\section{RESUMO}

Este artigo teve sua origem nas pesquisas desenvolvidas pelo Programa Institucional de Bolsas de Iniciação à Docência (Pibid), na FCT/UNESP, de Presidente Prudente/SP, sob orientação da Profa Dra Onaide Schwartz Mendonça. A metodologia da pesquisa resulta de uma investigação bibliográfica, cujo objetivo é refletir sobre os impactos produzidos pelas avaliações externas, especialmente a Avaliação Nacional da Alfabetização (ANA), no contexto do Pacto Nacional pela Alfabetização na Idade Certa (PNAIC), nas práticas pedagógicas, bem como suas implicações no cotidiano das salas de aula. O presente artigo visa contribuir para a compreensão do desenvolvimento dos possíveis processos de modificação das práticas pedagógicas bem como dos prováveis desdobramentos na aprendizagem dos alunos. A pesquisa revelou que, além de as avaliações externas não promoverem o desenvolvimento processual e integral do aluno, ainda constatou, que a direção das escolas tende a responsabilizar o professor pelo sucesso ou fracasso do aluno.

Palavras-chave: Alfabetização; Analfabetismo; Políticas Públicas Educacionais; Avaliação Externa.

IMPLICATIONS OF EXTERNAL LITERACY ASSESSMENTS.

\begin{abstract}
This article had its origin in the researches developed by the Institutional Program of Initiatives for Teaching (Pibid), at FCT / UNESP, Presidente Prudente / SP. The methodology of the research results from a bibliographical research, whose objective is to reflect on the impacts produced by external evaluations, especially the National Literacy Assessment (ANA), in the context of the National Pact for Literacy in the Right Age (PNAIC), pedagogical practices, as well as their implications in the everyday classroom. The present article aims to contribute to the understanding of the development of possible processes of modification of pedagogical practices as well as the probable unfolding in the students' learning. The research revealed that the external evaluations do not promote the procedural and integral development of the student, and that the direction of the schools tends to hold the teacher responsible for the success or failure of the student.
\end{abstract}

Keywords: Literacy; Illiteracy; Public Educational Policies;External Evaluation. 


\section{INTRODUÇÃO}

Desde meados da década de 1990 avaliações educacionais em larga escala vêm sendo utilizadas no Brasil, por meio da implantação do Sistema de Avaliação da Educação Brasileira (SAEB). Assim, tais avaliações já fazem parte do cotidiano dos docentes e de boa parte da população, além de ocupar lugar de destaque nas discussões educacionais em nosso país.

A Avaliação Nacional da Alfabetização (ANA), foco do presente estudo, configura-se como o mais recente elemento do SAEB, estando vinculada às ações do Pacto Nacional pela Alfabetização na Idade Certa (PNAIC), implementado em nível nacional pelo governo federal em 2012. Desse modo, a ANA se constitui em uma das estratégias do PNAIC para garantir a alfabetização plena de todas as crianças brasileiras até os 8 anos de idade, ou seja, é apresentada como uma ferramenta à disposição do professor para monitorar as aprendizagens dos alunos, contribuindo para a erradicação do analfabetismo no Brasil.

De acordo com Amorin (2015), a proposta do PNAIC surge como algo inovador no contexto educacional brasileiro frente ao que se havia implementado até o momento. Em suas ações, foi proposto um conjunto integrado de programas, materiais e referenciais curriculares e pedagógicos, disponibilizados pelo Ministério da Educação que contribuem para a alfabetização e o letramento, tendo como eixo principal a formação continuada dos professores alfabetizadores. No entanto, a autora ressalta que, a adesão ao "Pacto" implica, necessariamente, em aderir a todas as suas ações que vão muito além da formação continuada de professores alfabetizadores, "incluem, entre outras coisas, o monitoramento da aprendizagem de conteúdo específico, por meio da Provinha Brasil (aplicada aos alunos do 20 ano) e da aferição de aprendizagem de outros conteúdos específicos ao final do 3 ano de escolaridade" (LINO, 2014,p. 4) por meio da ANA que aconteceu pela primeira vez, no ano de 2013 em todos os municípios brasileiros que aderiram ao Pacto.

Este estudo pretende apresentar uma análise crítica da ANA, no contexto do PNAIC, feita a partir da utilização de referencial teórico elaborado por autores que já vêm abordando a questão da alfabetização, analfabetismo e avaliações externas destinadas à alfabetização, documentos referentes às legislações, resoluções pertinentes à elaboração e implementação do Pacto Nacional pela Alfabetização na Idade Certa (PNAIC) - política pública destinada à erradicação do analfabetismo no Brasil, a qual a ANA encontra-se atrelada-, além do próprio material produzido pela equipe do Pacto e visa contribuir para a compreensão do desenvolvimento dos possíveis processos de modificação das práticas pedagógicas bem como dos prováveis desdobramentos na aprendizagem dos alunos.

\section{METODOLOGIA}

O estudo foi realizado a partir da utilização de uma metodologia do tipo qualitativa e teve como fonte de coleta de dados e informações, a pesquisa documental e bibliográfica. Quanto aos objetivos propostos, o tipo de pesquisa eleita foi à exploratória. Nossa participação junto ao Programa Institucional de Bolsas de Iniciação à Docência (Pibid), desenvolvido na FCT/UNESP, de Presidente Prudente/SP, tem nos levado a vivências dúbias em relação ao PNAIC e suas ações.

Sentimo-nos perturbadas, incomodadas, com os desdobramentos das avaliações externas no contexto das salas de alfabetização. Foi dessa angústia que nasceu nosso interesse pela temática dessa pesquisa, pois, a análise do material elaborado pela equipe do PNAIC revela, em muitos momentos, foco centrado no controle do trabalho realizado pelo professor, atingindo "não somente as aprendizagens das crianças, mas também a sua própria conduta" (DICKEL, 2016, p. 200). Esse controle do trabalho do professor e seus desdobramentos negativos em sala de aula serão analisados a partir daqui. 


\section{RESULTADOS}

Os estudos e as estatísticas disponíveis apontam para uma realidade preocupante no que tange à aprendizagem dos alunos dos primeiros anos de escolaridade no Brasil. Revelam que somos um país de analfabetos, com crescimento baixo do PIB, insuficiente industrialização e, no ano de 2011, ocupávamos o 88. lugar entre 127 países no ranking de educação. Este ranking foi realizado pela Organização das Nações Unidas para a Educação, a Ciência e a Cultura (UNESCO), o braço da Organização das Nações Unidas (ONU) para a cultura e educação, em que o Brasil ficou atrás de países como a Argentina, o Chile, o Equador e a Bolívia (SOARES, 2008), países que apresentam importantes problemas sociais (AMORIN, 2015).

Dados apresentados pelo "Movimento Todos pela Educação" no ano de 2010, revelam que cerca de 45 a $50 \%$ dos alunos matriculados no Ensino Fundamental da rede pública no Brasil, possuem desempenho abaixo do mínimo esperado em leitura e, no que se refere à escrita, este número sobe para alarmantes $90 \%$. O fracasso e as dificuldades vivenciadas nos primeiros anos de escolaridade tendem a se estender ao longo dos anos posteriores.

O MEC condena a reprovação de crianças nos primeiros anos do Ensino Fundamental e, em seu discurso oficial, argumenta que, reprovar, é culpar o aluno pelo seu fracasso, isentando a escola de sua parcela de responsabilidade que, com isso, não se vê forçada a discutir a melhoria do processo de ensino e da aprendizagem.

A principal meta do PNAIC era alfabetizar todas as crianças brasileiras até os oito anos de idade, com vistas à erradicação do analfabetismo no Brasil, contando com a participação articulada dos governos federal, estaduais e municipais, que se propuseram a mobilizar todos os seus esforços e recursos na valorização e apoio aos professores e às escolas, por meio da disponibilização de materiais didáticos de alta qualidade destinados aos alunos e implementação de sistemas de avaliação, gestão e monitoramento, conforme o Art.1ำ da portaria 867 de 04 de julho de 2012 do Ministério da Educação, publicado no Diário Oficial da União n 129, quintafeira, 05 de julho de 2012. Este texto legal afirma que:

Fica instituído o Pacto Nacional pela Alfabetização na Idade Certa, pelo qual o Ministério da Educação (MEC) e as secretarias estaduais, distrital e municipais de educação reafirmam e ampliam o compromisso previsto no Decreto no 6.094, de 24 de abril de 2007, de alfabetizar as crianças até, no máximo, os oito anos de idade, ao final do 3 o ano do ensino fundamental, aferindo os resultados por exame periódico específico, que passa a abranger: I - a alfabetização em língua portuguesa e em matemática; II - a realização de avaliações anuais universais, pelo Instituto Nacional de Estudos e Pesquisas Educacionais Anísio Teixeira - INEP, para os concluintes do 3 o ano do ensino fundamental; III - o apoio gerencial dos estados, aos municípios que tenham aderido às ações do Pacto, para sua efetiva implementação. Parágrafo único. A pactuação com cada ente federado será formalizada em instrumento próprio a ser disponibilizado pelo MEC. (Disponível em: http://pacto.mec.gov.br/documentos-importantes)

Essa meta audaciosa de alfabetizar todas as crianças brasileiras até os 8 anos de idade não chega a ser uma inovação trazida pelo PNAIC. Na verdade, trata-se de uma meta proposta pelo Plano Nacional de Educação (PNE) que, conforme a lei 13.005/14 estabelece um elenco de diretrizes para atender: a erradicação do analfabetismo; o atendimento escolar universalizado; a superação das desigualdades educacionais e a erradicação de todas as formas de discriminação; a melhoria da qualidade de ensino; a formação para o trabalho e para o exercício da cidadania; a democratização da gestão escolar pública; a promoção humanística, científica, cultural e tecnológica; a efetiva aplicação de recursos públicos em educação; a valorização dos profissionais 
da educação; a promoção dos princípios de respeito aos direitos humanos, à diversidade e à sustentabilidade socioambiental (SANTOS, 2014).

Buscaremos a partir daqui, desvelar os mecanismos utilizados pela ANA no controle das práticas pedagógicas do professor, quais os impactos dessa avaliação externa destinada à alfabetização na sociedade brasileira, analisar os resultados parciais obtidos a partir da implementação da ANA no que se refere à erradicação do analfabetismo no Brasil, bem como revelar a importância dada à realidade das escolas e dos alunos na análise desses resultados.

\section{DISCUSSÃO}

\section{ANA, SUAS CONFIGURAÇÕES E DESDOBRAMENTOS NA PRÁTICA PEDAGÓGICA DOS PROFESSORES ALFABETIZADORES}

Nos parece claro que as avaliações externas padronizadas em larga escala de modo geral e a ANA em particular, geram uma série de tensões, ansiedade, competição (haja visto que, em alguns casos, encontram-se atreladas a uma política de bonificação por desempenho), desconfiança e até mesmo insegurança no professorado de escolas públicas.

A aplicação da ANA nos anos de 2013 e 2014 em todas as salas de 3.o ano do Ensino Fundamental nos municípios que aderiram ao PNAIC, os resultados, segundo Cruz, Teixeira e Souza (2016), indicam pouca melhora no panorama da alfabetização no Brasil e revelam dados preocupantes, tais como: uma a cada cinco crianças matriculadas no 3.0 ano do Ciclo de Alfabetização desenvolveu somente a capacidade de ler palavras simples em listas e que, uma quantidade pouco significativa de crianças demonstrou atingir níveis mais elevados de proficiência na leitura e escrita.

Embora em nenhum momento os documentos oficiais do PNAIC por nós analisados façam referência a possíveis aspectos negativos presentes no cerne das avaliações externas, precisamos deixar claro que nossos estudos apontam para a existência de tais aspectos, dentre os quais destacamos: a possibilidade de algumas escolas/professores - motivados pela pressão sofrida por instâncias superiores por bons resultados-, realizarem uma espécie de "treinamento" para um bom desempenho na avaliação.

A realização desse tipo de treinamento pode se efetivar por meio de aplicação de simulados nos mesmos moldes da ANA e pela eleição de conteúdos e conceitos contemplados pela prova em detrimento de conceitos e conteúdo igualmente importantes ao desenvolvimento integral do aluno.

Precisamos destacar também, que o PNAIC não prevê, em suas ações, uma política de plano de carreira para os professores e demais profissionais da educação, ao contrário, fala-se na instituição de uma espécie de bonificação por desempenho, a partir dos resultados expressos nas avaliações externas como Provinha Brasil e Avaliação Nacional da Alfabetização (ANA), de modo semelhante ao que atualmente existe na Secretaria Estadual de Educação do Estado de São Paulo, em que o valor do bônus recebido pelo professor está diretamente atrelado ao desempenho de seus alunos no Sistema de Avaliação de Rendimento Escolar do Estado de São Paulo (SARESP).

Outro aspecto negativo da ANA que precisamos destacar refere-se à padronização das provas. De acordo com Marafiga e Lopes (2013), o fato de as provas serem iguais para o Brasil, inviabilizam a possibilidade de se considerar as especificidades regionais e a diversidade cultural. De modo semelhante, desconsideram o contexto em que aluno e escola estão inseridos, com isso, tais provas não dão conta, em nosso entendimento, de cumprir com seu papel principal que é traçar um panorama real da qualidade da educação. Entendemos que, ao desconsiderar o processo de aprendizagem do aluno, acabam por medir quantitativamente sua aprendizagem. 


\section{CONCLUSÃO}

Primeiramente, gostaríamos de destacar aqui que, quaisquer que sejam as políticas públicas educacionais, elas precisam contar com o apoio do professorado para que deem certo. Sem a adesão e o convencimento por parte dos professores de que determinada estratégia tem validade prática, as políticas educacionais estão fadadas ao fracasso, já que o professor é um dos principais agentes da educação. Tal afirmação é válida tanto para as políticas públicas destinadas à alfabetização, como é o caso do PNAIC, quanto para as políticas de avaliação externa em larga escala, como é o caso da ANA. Em nossa concepção, sem as pressões e as restrições impostas pelo sistema de implementação da ANA, os professores, certamente, estariam mais propensos a aderir livremente. É preciso considerarmos que constatar o fracasso de seus alunos, já é, por si só, motivo de angústia para o professor, além de se constituir em motivo mais do que suficiente para impulsionar sua busca por novas metodologias e desenvolver estratégias de ensino diversas.

Ver o desempenho de seus alunos exposto na mídia, perceber que seu trabalho sofre controle externo, sentir-se responsabilizado pela queda e/ou ascensão de sua escola num esquema esdrúxulo de ranqueamento entre escolas e professores, realmente não parece atrativo à adesão de seja lá o que for. Professores precisam ser parceiros, estabelecer troca de experiência e estratégias de ensino no cotidiano escolar e não competidores, ávidos por serem eleitos os melhores ou receberem alguns reais a mais de bônus do que o colega.

\section{REFERÊNCIAS}

AMORIN, P. R. Pacto Nacional pela Alfabetização na Idade Certa (PNAIC-2012): Análise e Perspectiva de Ação. Dissertação de Mestrado. Universidade do Oeste Paulista - Unoeste, Presidente Prudente, SP, 2015.

CRUZ, M. do C. S.; TAVEIRA, A. de S.; SOUZA, S. L. Avaliação Nacional da Alfabetização (ANA): Contribuições deste Instrumento na Percepção de Gestores e Professores. Meta: Avaliação. Rio de Janeiro, v.8, n.23, p. 183-215, maio/ago. 2016.

CRUZ, M. do C. S. Ciclo de alfabetização e avaliação: progressão escolar e das aprendizagens. Brasília, DF: MEC; SEB, 2015. (Caderno para Gestores).

DICKEL, A. A Avaliação Nacional da Alfabetização no contextodo Sistema de Avaliaçãoda Educação Básica e do Pacto Nacional pela Alfabetização na idade Certa: Responsabilização e Controle. Cadernos Cedes, Campinas, v. 36, n. 99, p. 193-206, maio-ago. 2016.

LINO, C. de S. Avaliação Nacional da Alfabetização (ANA) no contexto doPacto Nacional Pela Alfabetização Na Idade Certa (PNAIC): apontamentos de uma pesquisa. - GEPAC/UNIRIO/ Secretaria Municipal de Educação/Duque de Caxias, RJ, Brasil, 2014.Disponível em: abalf.org.br/.../Avaliação-Nacional-Da-Alfabetização-ANA-No-Cont.... Acesso em 19/07/2017.

MARAFIGA, A. W.; LOPES, A. R. L. V. Avaliações Externas e a sua Implicação na Escola: alguns apontamentos. IX Congresso Nacional de Educação - EDUCERE- Pontifícia Universidade Católica do Paraná. Curitiba, de 23 a 26 de set. 2013.

SANTOS, R. B. dos; CORDEIRO, R. V.; SGARBI, A. D. O Pacto Nacional pela Alfabetização na idade certa e a educação plena: dialogando com a alfabetização científica nos anos iniciais do ensino fundamental. In: SIMPÓSIO NACIONAL DE ENSINO DE CIÊNCIA E TECNOLOGIA- SINECT, 4. 2014, Ponta Grossa. Anais. Ponta Grossa: SINECT, 2014. 
SOARES, L. H. et al. Globalização e desafios contemporâneos para educação - análise do Pisa e os rumos da educação no Brasil. Espaço do Currículo, v.1, n.1, p.189-222, Março-

Setembro/2008.Disponível em: <www.aepppc.org.br/revista>. Acesso em: 08 jul.2017. 